\title{
An approach for the response of buildings subjected to impact load after soft-story failure due to earthquake excitation
}

\author{
Wojciech Migda* and Robert Jankowski \\ Faculty of Civil and Environmental Engineering, Gdansk University of Technology, Gdansk, Poland
}

Received 19 November 2012

Revised 15 January 2013

Accepted 22 January 2013

\begin{abstract}
The soft-story failure is one of the most typical types of damage observed in buildings during earthquakes. The failure of an intermediate soft story of a structure results in large impact loading acting on the lower floors due to the fall of the upper stories. The aim of the present paper is to study the behavior of the structural members exposed to such extreme load conditions occurring under ground motion excitation. Special attention is paid to investigate the influence of the degradation of horizontal stiffness of columns on the response of the building during earthquake. The results of the study show that the stiffness degradation of building columns, due to impact caused by the fall of the upper stories, may have a considerable influence on the structural response. Moreover, the results clearly indicate that the time of impact plays a substantial role in the overall behavior of the building suffering from the soft-story failure. It has been shown that the structural response may be increased significantly if impact takes place when the building is in the range of its peak deformations during the earthquake, especially when the structure is just approaching the extreme position.
\end{abstract}

Keywords: Stiffness degradation, soft-story failure, impact, earthquakes

\section{Introduction}

The soft-story failure is considered to be one of the most typical types of damage observed in buildings during earthquakes. In the 1989 Loma Prieta earthquake, for example, many wood-frame buildings in the Marina District experienced permanent offsets of their soft stories [1]. As the result of the Hyougoken-Nanbu (Kobe) earthquake of 1995, a large number of the damaged steel and reinforced concrete buildings suffered from failure of the first or intermediate story due to lack of lateral strength as well as ductility of columns [2,3]. The soft-story failure was also common during the 2004 Asia earthquake resulting in major damage in downtown of Banda Aceh [4]. It was observed during ground motions that the failure of an intermediate soft story of a building leads to large impact loading acting on the lower floors due to the fall of the upper stories. If the resistance of the structural members of the lower stories is not sufficient the progressive collapse of the whole building may be initiated leading to increased material damages as well as human loses.

The investigation on earthquake-induced impacts in buildings has been conducted in earthquake engineering for more than two decades now. However, all of the previous studies were nearly exclusively focused on horizontal structural interactions observed during earthquakes as the result of the difference in dynamic properties of neighboring

\footnotetext{
${ }^{*}$ Corresponding author: Wojciech Migda, Faculty of Civil and Environmental Engineering, Gdansk University of Technology, ul. Narutowicza 11/12, 80-233 Gdansk, Poland. Tel.: +48 58347 2200; Fax: +48 58347 1670; E-mail: wmigda@pg.gda.pl.
} 
buildings. This phenomenon, known as the earthquake-induced structural pounding, may lead to substantial damage or even collapse of colliding structures. The basic investigation on pounding between insufficiently separated buildings in series, modeled as single degree-of-freedom systems, was carried out by Anagnostopoulos [5]. Davis [6] used this simple structural model to study pounding of a building against a rigid adjacent structure. Single-degreeof-freedom models were also employed by other researchers (see, for example, [7-10]). More detailed analyses were carried out using discrete multi degree-of-freedom structural models, in which mass of each story was lumped at each floor level. A number of studies using such numerical models were conducted for isolated and non-isolated buildings with different heights, story masses and stiffness properties (see [11-15]). The research on earthquakeinduced pounding was also conducted using the Finite Element Method (FEM). The method was employed in the study conducted by Papadrakakis et al. [16], in which floors of colliding buildings were modeled as single four-node plane stress elements and walls as four linear beam-column elements. More accurate, three-dimensional non-linear analysis of pounding between two insufficiently separated buildings using FEM was recently carried out by Jankowski $[17,18]$.

On the contrary to the earthquake-induced horizontal collisions in buildings, impact between the damaged upper part of the building falling onto the lower stories after the soft-story failure has not been really studied so far. The experimental investigation on the behavior of horizontally deformed steel columns (deformation as the result of earthquake loading) that are additionally subjected to vertical impact load was conducted in [19]. In that study, however, the introduced pre-deformation was a static one and the influence of the dynamic effects of the ground motion was not considered (limitation of the experimental setup). The aim of the present paper is to study the behavior of the structural members of the building under real earthquake excitation subjected to vertical impact load after failure of the intermediate soft-story. Special attention is paid to investigate the influence of the horizontal stiffness degradation of columns on the overall structural response during the ground motion.

\section{Theoretical approach}

Let us consider a column of a building with both ends fixed to the floor slabs, which is exposed to bending (as the result of horizontal earthquake loading) and simultaneously to vertical load acting on its top (see Fig. 1). The case of the vertical load, which results only from the weight of the floor slab (static load) was studied by Juhasova [20]. In this paper let us consider a more general case, in which the vertical load results also from impact of the upper stories falling onto the top of a column after the soft-story failure (dynamic load).

Taking into account the theory of the second order (see, for example, [21]), the differential equation describing the deformation of the column at a given time, $t$, of the ground motion can be written as:

$$
E I \frac{\partial^{2} u(x, t)}{\partial x^{2}}+P(t) x+F(t) u(x, t)=0,
$$

where $E$ is the Young's modulus of elasticity, $I$ is the moment of inertia of the cross section, $u(x, t)$ denotes the horizontal displacement at the distance $x$ from the middle of the column (see Fig. 1), $P(t)$ is the horizontal inertial force due to earthquake loading and $F(t)$ stands for the vertical force, which consists of the weight of the floor slab as well as the load due to impact of the upper stories falling onto the top of the column after the soft-story failure. The general solution of Eq. (1) can be expressed as (compare [20]):

$$
u(x, t)=a(t) \sin (k(t) x)+b(t) \cos (k(t) x)-\frac{P(t) x}{E I k^{2}(t)},
$$

where

$$
k^{2}(t)=\frac{F(t)}{E I}, k(t) \geqslant 0 .
$$

Considering the boundary conditions (see direction of $x$ at Fig. 1), parameters $a(t)$ and $b(t)$ can be calculated as equal to: 
a) from the condition: $u(0, t)=0$ we have: $u(0, t)=b(t) \cos 0=0$, so: $b(t)=0$,

b) from the condition: $u^{\prime}\left(\frac{l}{2}, t\right)=0$ we have:

$$
u^{\prime}\left(\frac{l}{2}, t\right)=a(t) k(t) \cos \left(k(t) \frac{l}{2}\right)-\frac{P(t)}{E I k^{2}(t)}=0, \text { so: } a(t)=\frac{P(t)}{E I k^{3}(t) \cos \left(k(t) \frac{l}{2}\right)} .
$$

Substituting the derived values of $a(t)$ and $b(t)$ into Eq. (2) leads to:

$$
\begin{aligned}
& u(x, t)=\frac{P(t)}{E I k^{3}(t) \cos \left(k(t) \frac{l}{2}\right)} \sin (k(t) x)-\frac{P(t) x}{E I k^{2}(t)}, \\
& u(x, t)=\frac{P(t)}{E I k^{2}(t)}\left(\frac{\sin (k(t) x)}{k(t) \cos \left(k(t) \frac{l}{2}\right)}-x\right) .
\end{aligned}
$$

For $x=\frac{l}{2}$ we obtain:

$$
u\left(\frac{l}{2}, t\right)=\frac{P(t)}{E I k^{2}(t)}\left(\frac{\tan \left(k(t) \frac{l}{2}\right)}{k(t)}-\frac{l}{2}\right) .
$$

The total horizontal displacement of the upper support, $u(l, t)$, can be obtained from the following formula:

$$
u(l, t)=2 u\left(\frac{l}{2}, t\right)
$$

Substituting Eq. (6) into Eq. (7) yields:

$$
u(l, t)=\frac{2 P(t)}{E I k^{2}(t)}\left(\frac{\tan \left(k(t) \frac{l}{2}\right)}{k(t)}-\frac{l}{2}\right) .
$$

Neglecting the influence of horizontal damping at this stage of considerations, the horizontal stiffness of the column, $\bar{K}(t)$, can be obtained from the following formula:

$$
\bar{K}(t)=\frac{P(t)}{u(l, t)} .
$$

Substituting Eq. (8) into Eq. (9) leads to:

$$
\begin{aligned}
\bar{K}(t) & =\frac{E I k^{2}(t)}{2} \frac{2 k(t)}{2 \tan \left(k(t) \frac{l}{2}\right)-k(t) l}, \\
\bar{K}(t) & =\frac{E I k^{3}(t)}{2 \tan \left(k(t) \frac{l}{2}\right)-k(t) l} .
\end{aligned}
$$

The above relation can also be expressed in the form:

$$
\bar{K}(t)=\frac{12 E I}{l^{3}} \frac{k^{3}(t) l^{3}}{24 \tan \left(k(t) \frac{l}{2}\right)-12 k(t) l}=K \bar{d}(t),
$$

where:

$$
K=\frac{12 E I}{l^{3}}
$$

is the horizontal stiffness of the column fixed at both ends (see [21]) and

$$
\bar{d}(t)=\frac{k^{3}(t) l^{3}}{24 \tan \left(k(t) \frac{l}{2}\right)-12 k(t) l}
$$




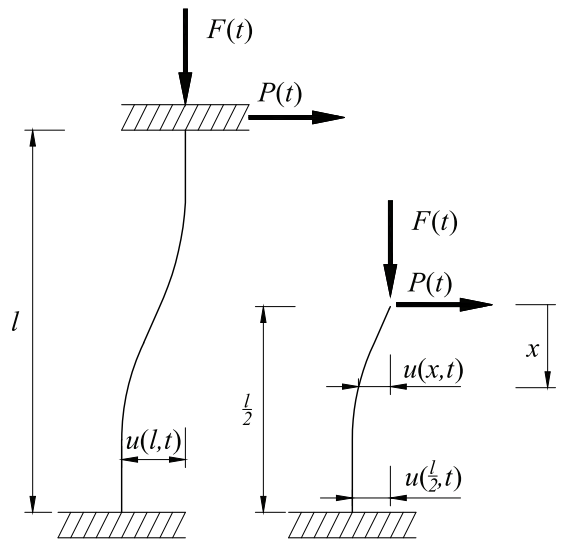

Fig. 1. Deformed column exposed to bending (as the result of horizontal earthquake loading) and simultaneously to vertical load acting on its top.

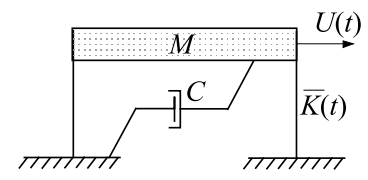

Fig. 3. Inelastic single degree-of-freedom system.

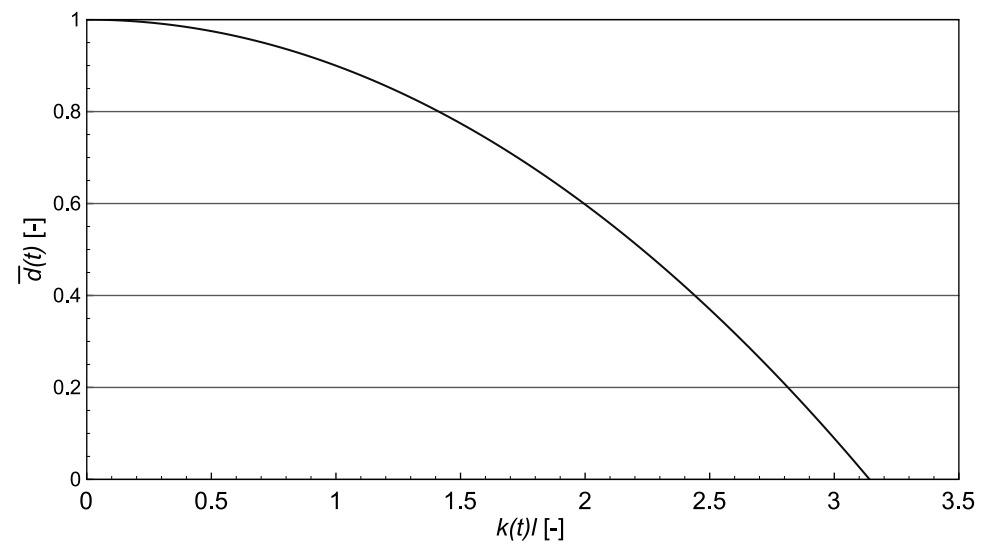

Fig. 2. Relation between the degradation parameter, $\bar{d}(t)$, and $k(t) l$.

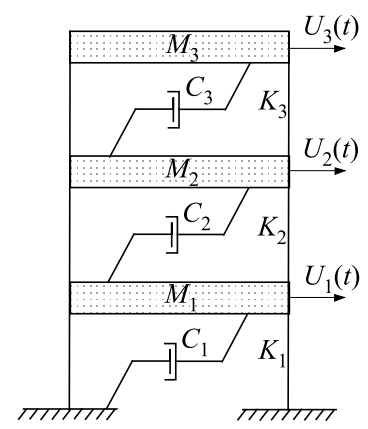

Fig. 4. Elastic three degree-of-freedom system.

is a parameter describing the degradation of the horizontal stiffness as the result of dynamic vertical load and is valued within the interval $(0,1)$ for $0<k(t) l<\pi$. The relation between $\bar{d}(t)$ and $k(t) l$ is shown at Fig. 2. It can be seen from the figure that the value of $\bar{d}(t)$ is nearly equal to 1 for small values of $k(t) l \in(0,0.2)$ indicating that, in this range, the influence of vertical dynamic load on the horizontal stiffness can be neglected. On the other hand, for higher values of $k(t) l$, the value of $\bar{d}(t)$ substantially decreases and for $k(t) l \rightarrow \pi$ the degradation parameter, $\bar{d}(t)$, tends to be equal to zero. From the condition $k(t) l \rightarrow \pi$, considering Eq. (3), one may determine the value of the vertical critical dynamic force, $F_{c r}(t)$, for which $\bar{K}(t) \rightarrow 0$ :

$$
F_{c r}(t)=\frac{\pi^{2} E I}{l^{2}}
$$

Comparing the value of the dynamic force $F_{c r}(t)$ described by Eq. (15) with the value of the vertical critical static force, $P_{c r}$, for the straight column fixed at both ends due to the loss of its stability (see [21]):

$$
P_{c r}=\frac{4 \pi^{2} E I}{l^{2}}
$$

we can draw the conclusion that: $P_{c r}=4 F_{c r}(t)$.

Considering Eq. (12), the dynamic equation of motion in the horizontal direction for a structure modeled as an inelastic single degree-of-freedom system (see Fig. 3) under earthquake excitation can be written as:

$$
M \ddot{U}(t)+C \dot{U}(t)+\bar{K}(t) U(t)=-M \ddot{U}_{g}(t),
$$

where $\ddot{U}(t), \dot{U}(t), U(t)$ is the horizontal acceleration, velocity and displacement of the structure with relation to the ground; $M, C, \bar{K}(t)$ is the mass, damping coefficient and inelastic stiffness coefficient, respectively; and $\ddot{U}_{g}(t)$ denotes the ground motion acceleration. 
It should be mentioned, that the inelastic stiffness coefficient, $\bar{K}(t)$, used in Eq. (17), might incorporate not only the degradation of horizontal stiffness of columns but also degradation of stiffness of other structural elements. It is quite an often situation when the seismic loads leads, for example, to the degradation of stiffness of joints between the columns and horizontal elements (beams or slabs). This effect might play a very important role in the response of buildings under earthquake excitation, especially in the case of buildings designed according to old standards or pilotis frame structures (see [22]).

\section{Numerical model}

In order to investigate the influence of stiffness degradation on the structural behavior under seismic excitation, a number of numerical simulations have been conducted. The study has been focused on the response of a threestory building, in which failure of the second and the third story is assumed to take place at different times of the earthquake and those upper stories fall onto the top slab of the first story. The analysis has been conducted in the following three phases (changes between particular phases make the analysis nonlinear):

\subsection{Response of the building before impact}

In the first phase of analysis (before impact), the building has been modeled as an elastic three degree-of-freedom system (see Fig. 4). The dynamic equation of motion for such a structural model under earthquake excitation can be formulated as:

$$
\begin{aligned}
& \mathbf{M} \ddot{\mathbf{U}}(t)+\mathbf{C} \dot{\mathbf{U}}(t)+\mathbf{K} \mathbf{U}(t)=-\mathbf{M} \mathbf{1} \ddot{U}_{g}(t), \\
& \mathbf{M}=\left[\begin{array}{lll}
M_{1} & & \\
& M_{2} & \\
& & \\
& M_{3}
\end{array}\right] ; \ddot{\mathbf{U}}(t)=\left[\begin{array}{l}
\ddot{U}_{1}(t) \\
\ddot{U}_{2}(t) \\
\ddot{U}_{3}(t)
\end{array}\right] ; \dot{\mathbf{U}}(t)=\left[\begin{array}{l}
\dot{U}_{1}(t) \\
\dot{U}_{2}(t) \\
\dot{U}_{3}(t)
\end{array}\right] ; \mathbf{U}(t)=\left[\begin{array}{l}
U_{1}(t) \\
U_{2}(t) \\
U_{3}(t)
\end{array}\right], \\
& \mathbf{C}=\left[\begin{array}{ccc}
C_{1}+C_{2} & -C_{2} & \\
-C_{2} & C_{2}+C_{3} & -C_{3} \\
& -C_{3} & C_{3}
\end{array}\right] ; \mathbf{K}=\left[\begin{array}{ccc}
K_{1}+K_{2} & -K_{2} & \\
-K_{2} & K_{2}+K_{3} & -K_{3} \\
& -K_{3} & K_{3}
\end{array}\right],
\end{aligned}
$$

where: $\ddot{U}_{i}(t), \dot{U}_{i}(t), U_{i}(t), K_{i}, C_{i}(i=1,2,3)$ is the horizontal acceleration, velocity, displacement, damping coefficient and elastic stiffness coefficient for a story with mass $M_{i}$, respectively.

\subsection{Response of the building during impact}

After failure of the second and the third story, the behavior of the remaining first story of the building has been modeled as an inelastic single degree-of-freedom system (see Fig. 3). The dynamic equation of motion formulated in Eq. (17) has been employed taking $M=M_{1}, C=C_{1}$ and $\bar{K}(t)$ determined according to Eq. (12). The displacement, velocity and acceleration of the first story, as obtained at the end of the previous phase for the three degree-of-freedom system, have been taken as the initial values. In this phase of the analysis, the vertical force, $F(t)$ (see Fig. 1), due to impact of the upper stories falling onto the top of the first story, has been calculated at each time step using the non-linear viscoelastic model of impact force expressed by the formula [23]:

$$
\begin{array}{ll}
F(t)=\bar{\beta} \delta^{\frac{3}{2}}(t)+\bar{c}(t) \dot{\delta}(t) & \text { for } \dot{\delta}(t)>0 \text { (approach period of impact), } \\
F(t)=\bar{\beta} \delta^{\frac{3}{2}}(t) & \text { for } \dot{\delta}(t) \leqslant 0 \text { (restitution period of impact), }
\end{array}
$$

where $\bar{\beta}$ is the impact stiffness parameter, $\delta(t)$ describes the relative deformation of colliding structural members and $\bar{c}(t)$ is the impact element's damping which, for the free fall of the second and the third story onto the top of the first story, can be obtained from the formula (compare [23]):

$$
\bar{c}(t)=2 \bar{\xi} \sqrt{\bar{\beta} \sqrt{\delta(t)} \frac{M_{1}\left(M_{2}+M_{3}\right)}{M_{1}+M_{2}+M_{3}}},
$$




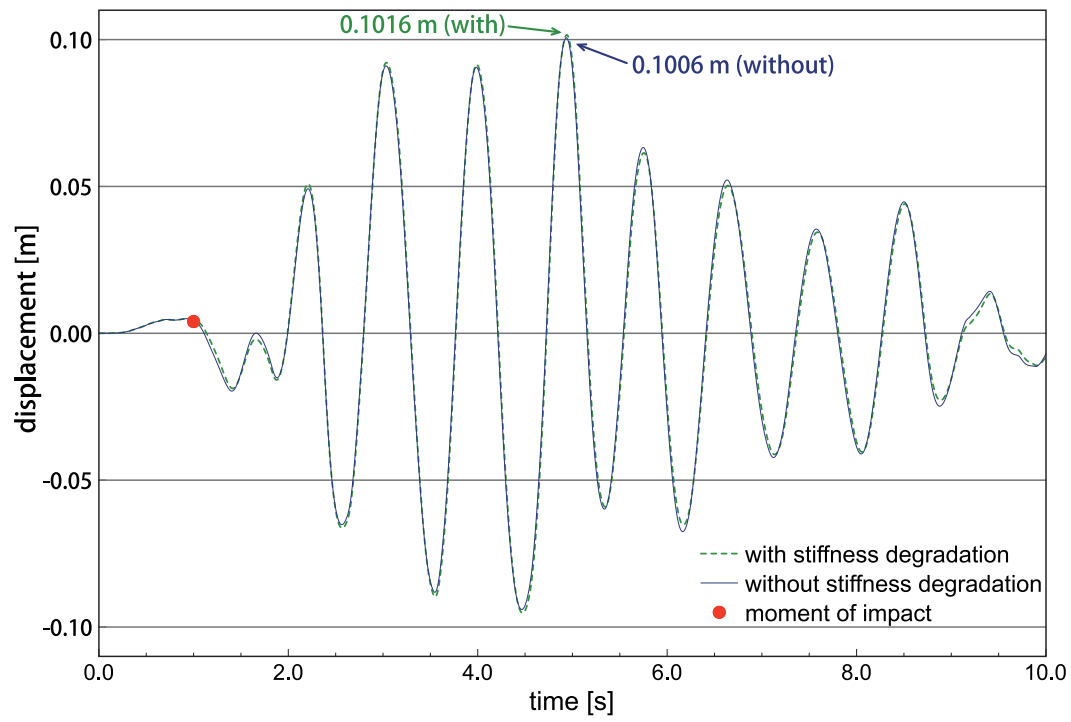

Fig. 5. Displacement time history of the first story of building under the El Centro earthquake with and without considering the degradation of horizontal stiffness for impact at $t=1 \mathrm{~s}$.

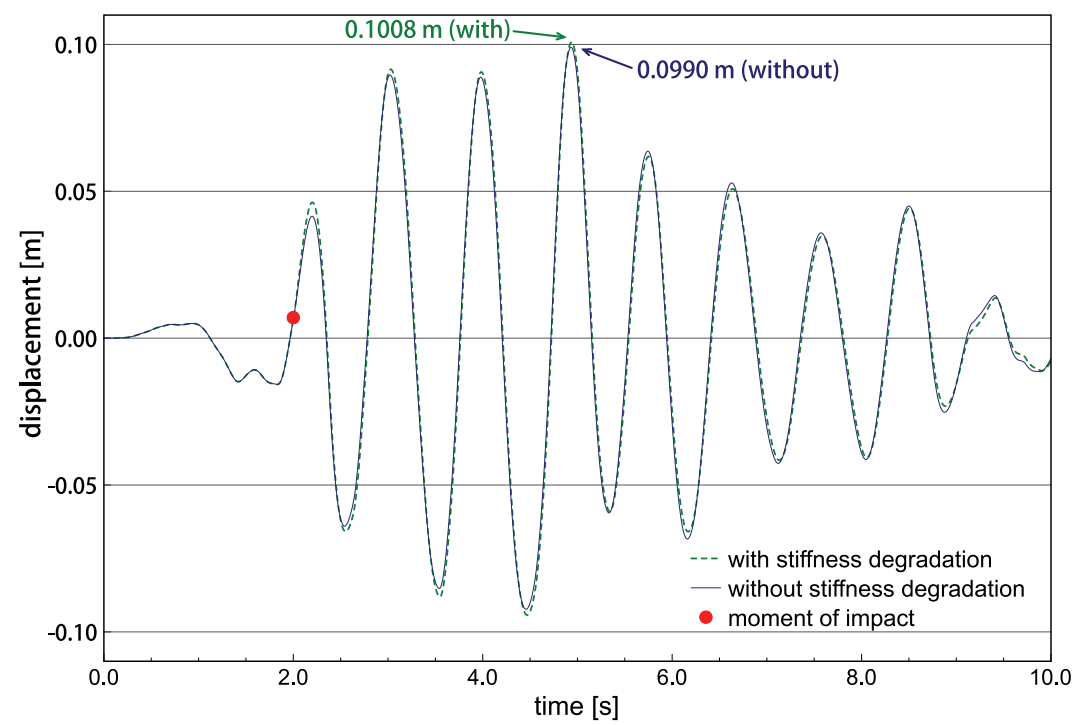

Fig. 6. Displacement time history of the first story of building under the El Centro earthquake with and without considering the degradation of horizontal stiffness for impact at $t=2 \mathrm{~s}$.

where $\bar{\xi}$ denotes the damping ratio related to a coefficient of restitution, $e$. The approximate relation between $\bar{\xi}$ and $e$ in the non-linear viscoelastic model can be expressed by the formula (see [10]):

$$
\bar{\xi}=\frac{9 \sqrt{5}}{2} \frac{1-e^{2}}{e(e(9 \pi-16)+16)} .
$$

\subsection{Response of the building after impact}

It has been assumed in the analysis that after impact the weight of the second and the third story stays at the top of the remaining first story and the building has also been modeled as an inelastic single degree-of-freedom system 
Table 1

Peak displacement values under the El Centro earthquake for different cases of impact times

\begin{tabular}{cccc}
\hline Time of impact $s$ & \multicolumn{2}{c}{ Peak displacement $m$} & Increase \% \\
\cline { 2 - 3 } & With stiffness degradation & Without stiffness degradation & \\
\hline 1 & 0.1016 & 0.1006 & 0.99 \\
2 & 0.1008 & 0.0990 & 1.82 \\
3 & 0.0883 & 0.0795 & 11.1 \\
4 & 0.0551 & 0.0551 & - \\
5 & 0.0778 & 0.0736 & 5.71 \\
6 & 0.0723 & 0.0554 & 30.5 \\
7 & 0.0613 & 0.0613 & - \\
8 & 0.0613 & 0.0613 & - \\
9 & 0.0613 & 0.0613 & - \\
\hline
\end{tabular}

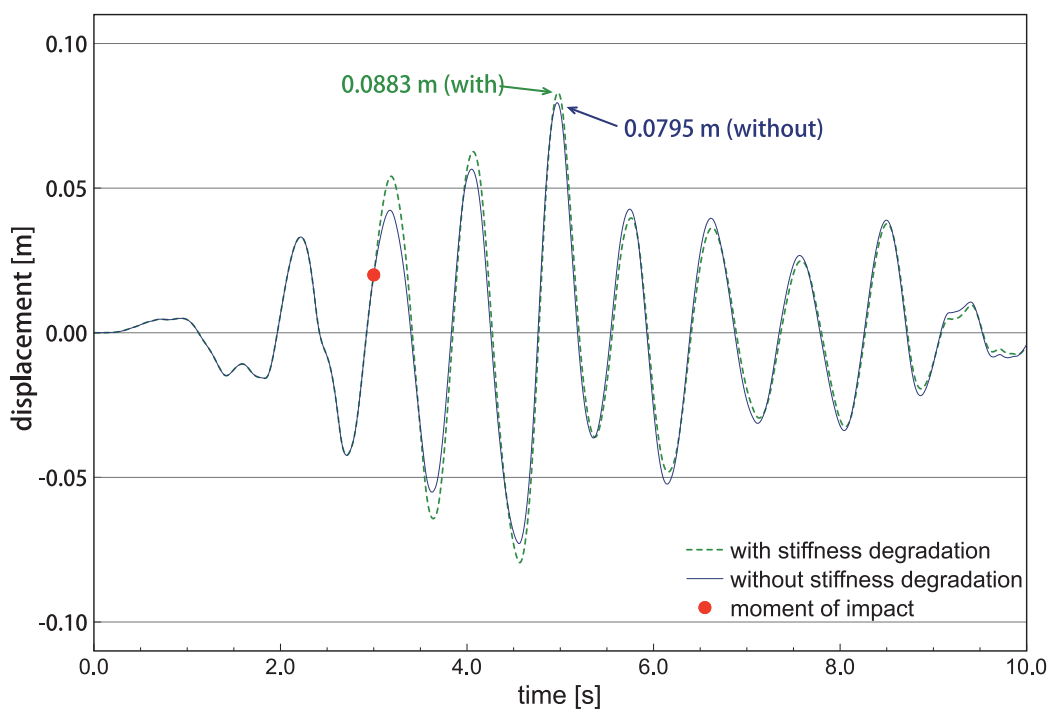

Fig. 7. Displacement time history of the first story of building under the El Centro earthquake with and without considering the degradation of horizontal stiffness for impact at $t=3 \mathrm{~s}$.

(see Fig. 3). The dynamic equation of motion formulated in Eq. (17) has been used taking $M=M_{1}+M_{2}+M_{3}$, $C=C_{1}$ and $\bar{K}(t)$ determined according to Eq. (12). In this phase of the analysis, the constant value of the vertical force, $F(t)=\left(M_{1}+M_{2}+M_{3}\right) g$ ( $g$ is the gravity acceleration), which results only from the weight of all floor slabs, has been applied.

\section{Results of numerical simulations}

The numerical simulations have been focused on the behavior of a three-story building, in which failure of the second and the third story is assumed to take place at different times of the earthquake and those upper stories fall onto the top slab of the first story. The following values describing the structural properties of the intact building have been used in the analysis (see [14]): $M_{1}=M_{2}=M_{3}=25 \times 10^{3} \mathrm{~kg}, K_{1}=K_{2}=K_{3}=3.460 \times 10^{6} \mathrm{~N} / \mathrm{m}$, $C_{1}=C_{2}=C_{3}=6.609 \times 10^{4} \mathrm{~kg} / \mathrm{s}$ (structural damping ratio, $\xi=0.05$ ), $l=3.5 \mathrm{~m}$. The values of the non-linear viscoelastic impact force model's parameters have been applied as equal to: $\bar{\beta}=2.75 \times 10^{9} \mathrm{~N} / \mathrm{m}^{3 / 2}, \bar{\xi}=0.35$ $(e=0.65)$ (see [14,23]). In order to solve the equations of motion Eqs (17) and (18) numerically, the time-stepping Newmark method [24], with the standard parameters: $\gamma_{N}=0.5, \beta_{N}=0.25$ (see [25]) and constant time step $\Delta t=0.0002 \mathrm{~s}$, has been used. The numerical procedure has been programmed using MATLAB software. The NS component of the El Centro earthquake (18.05.1940) has been applied in the analysis. 


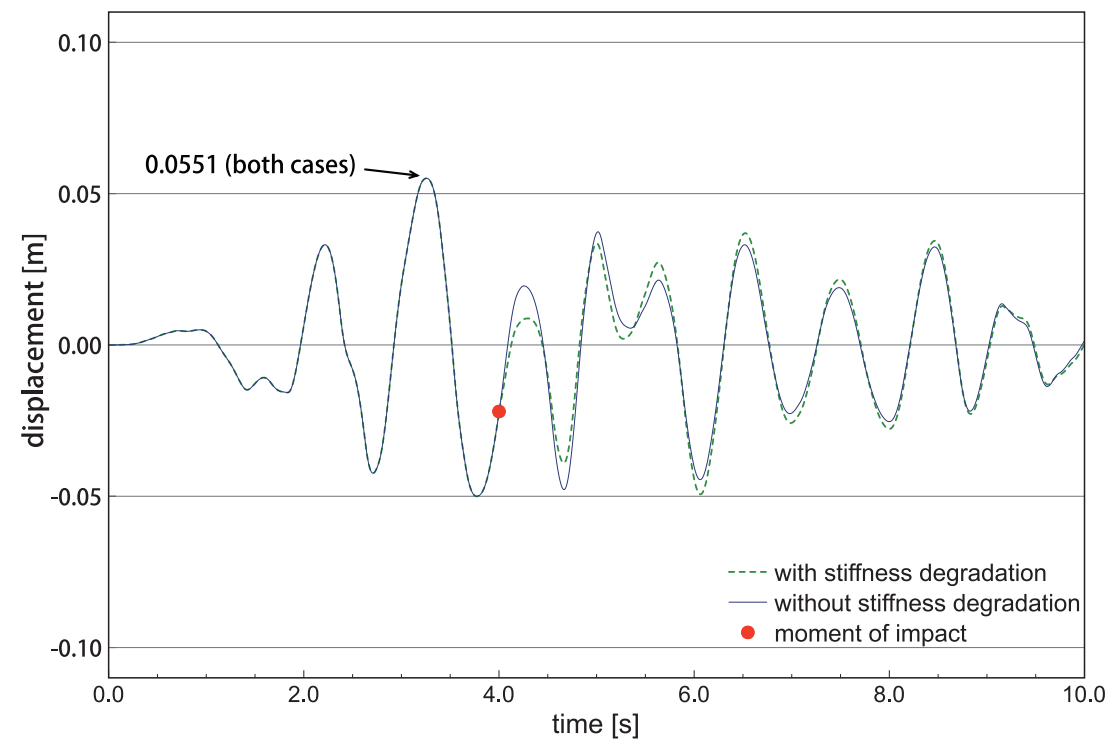

Fig. 8. Displacement time history of the first story of building under the El Centro earthquake with and without considering the degradation of horizontal stiffness for impact at $t=4 \mathrm{~s}$.

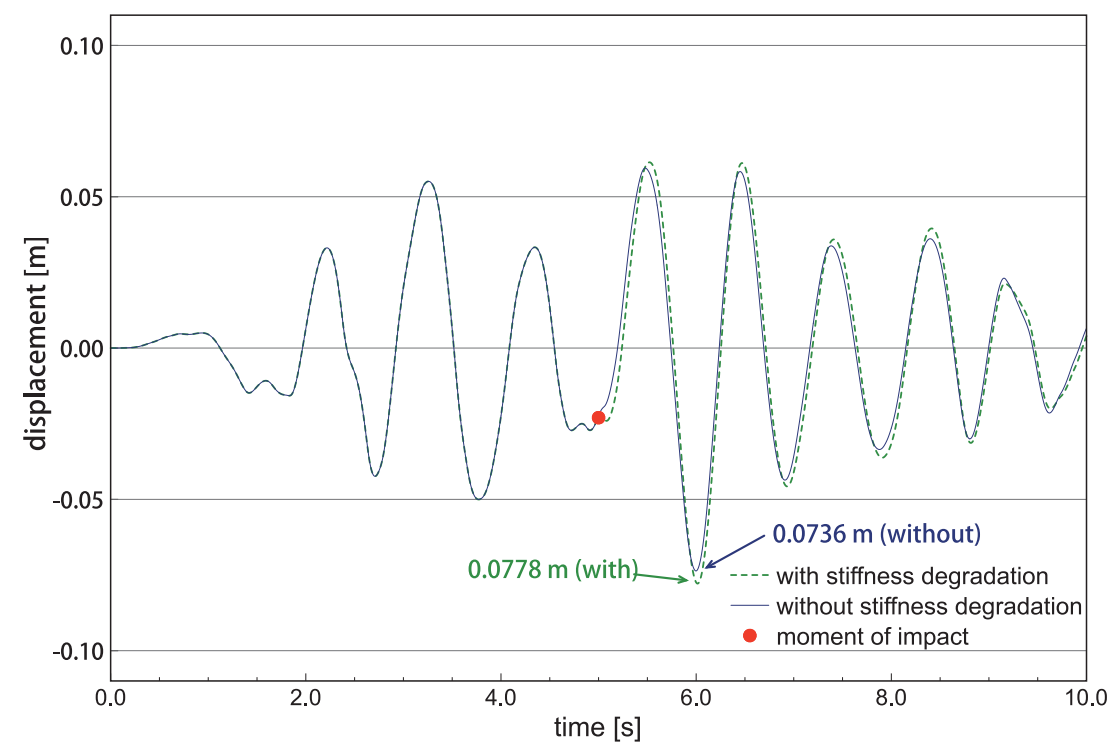

Fig. 9. Displacement time history of the first story of building under the El Centro earthquake with and without considering the degradation of horizontal stiffness for impact at $t=5 \mathrm{~s}$.

The analysis has been conducted for two cases. First, the response of the building has been determined taking into account the degradation of horizontal stiffness of columns under seismic excitation and vertical load. Then, a similar analysis has been carried out without considering the effect of stiffness degradation. It has been assumed in the analysis that impact (due to the fall of the upper stories onto the top of the first story) takes place at different times of the earthquake. The examples of the results, for impact at $t=1 \mathrm{~s}, t=2 \mathrm{~s}, t=3 \mathrm{~s}, t=4 \mathrm{~s}, t=5 \mathrm{~s}$, $t=6 \mathrm{~s}, t=7 \mathrm{~s}, t=8 \mathrm{~s}$ and $t=9 \mathrm{~s}$ of the El Centro earthquake, are shown in Figs 5-13. The peak displacement response values for different cases of impact times are denoted in the figures by arrows and also summarized in Table 1. Additionally, Fig. 14 presents the impact force, $F(t)$, relative vertical deformation of colliding structural members, $\delta(t)$, and the impact element's damping time histories during impact, $\bar{c}(t)$, which gives some insight into 




Fig. 10. Displacement time history of the first story of building under the El Centro earthquake with and without considering the degradation of horizontal stiffness for impact at $t=6 \mathrm{~s}$.

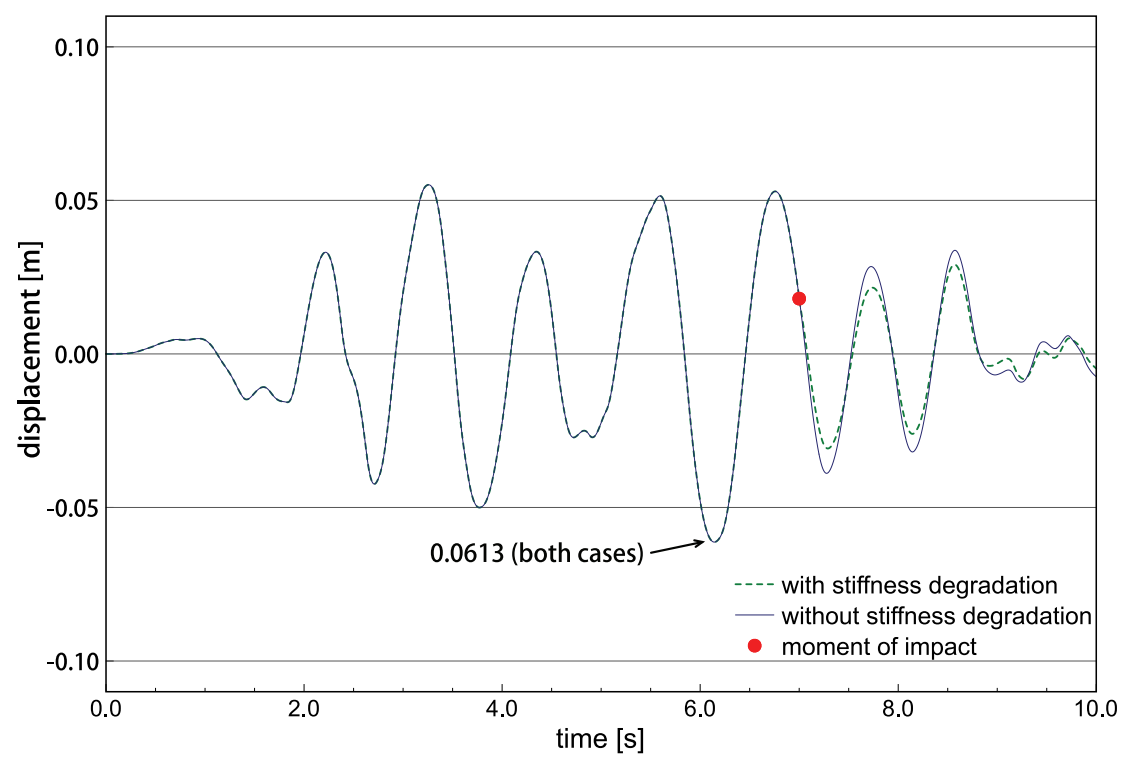

Fig. 11. Displacement time history of the first story of building under the El Centro earthquake with and without considering the degradation of horizontal stiffness for impact at $t=7 \mathrm{~s}$.

the model of impact force defined in Eqs (19)-(21).

It can be seen from Figs 5-13 that incorporation in the numerical analysis the degradation of horizontal stiffness has a considerable influence on the structural behavior under earthquake excitation. In nearly all of the cases the stiffness degradation leads to the increase in the response of the first story of building (the only exception is the reduced response shown in Fig. 11 for impact at $t=7 \mathrm{~s}$ ). Moreover, the curves shown in Figs 5-13 indicate that the time of impact plays a substantial role in the overall behavior of the structure. It can be seen from Figs 7, 9, 10 and 13 that, for the case when impact takes place when the structure is in the range of its peak deformations during the earthquake, the increase in the structural response can be really substantial (especially in the case when the structure 


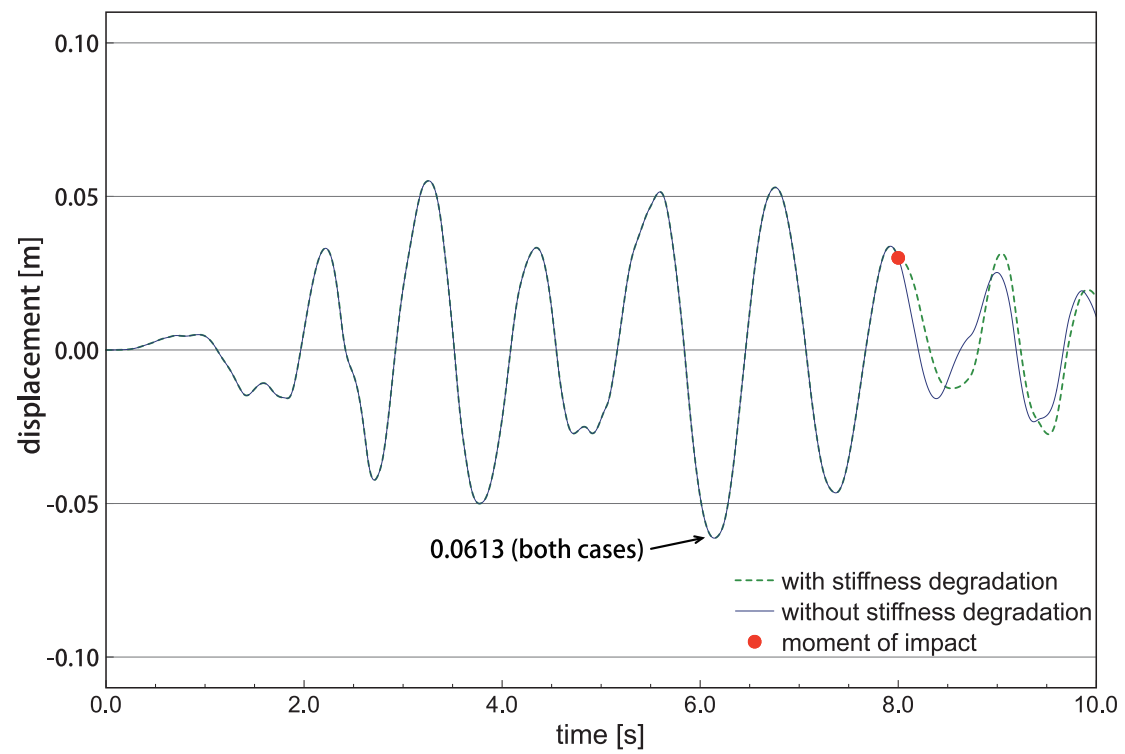

Fig. 12. Displacement time history of the first story of building under the El Centro earthquake with and without considering the degradation of horizontal stiffness for impact at $t=8 \mathrm{~s}$.

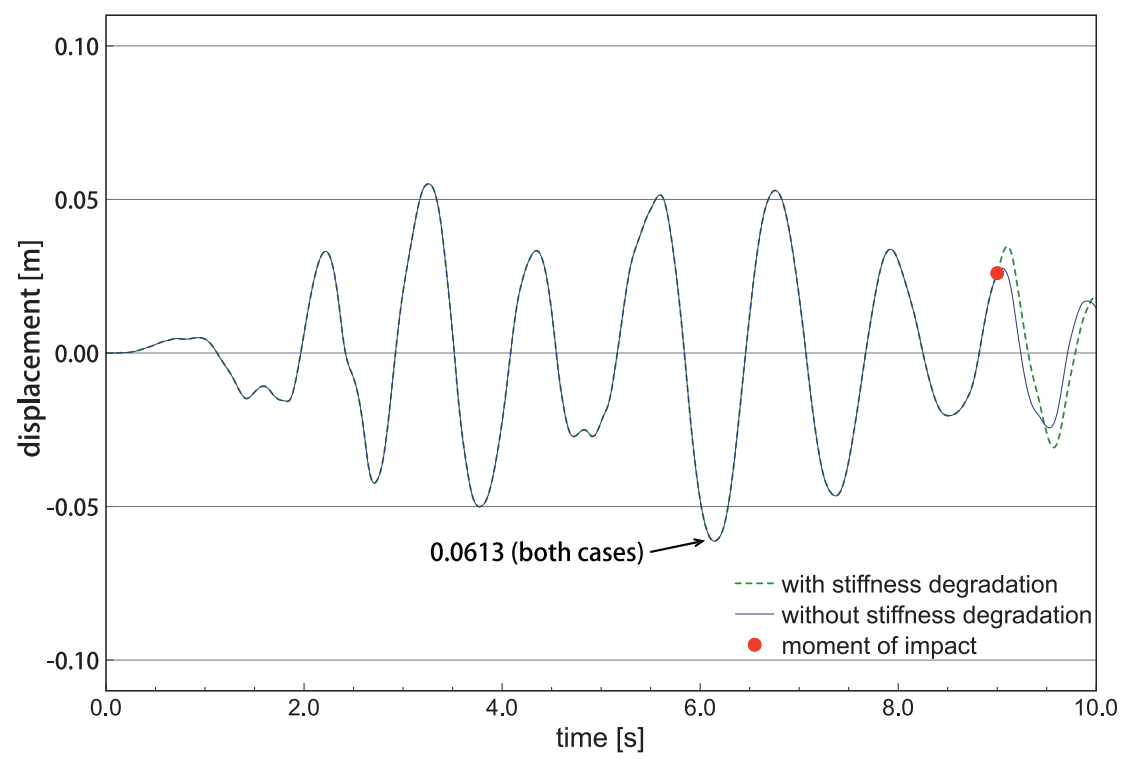

Fig. 13. Displacement time history of the first story of building under the El Centro earthquake with and without considering the degradation of horizontal stiffness for impact at $t=9 \mathrm{~s}$.

is just approaching its extreme position). In the case of impact at $t=6 \mathrm{~s}$ (see Fig. 10), for example, the increase in the peak displacement due to the degradation of horizontal stiffness is as high as $30.5 \%$. Relatively high increase in the peak displacement value (by 11.1\%) can also be observed in Fig. 7 obtained for impact at $t=3 \mathrm{~s}$. On the other hand, when impact takes place when the displacement of the building is relatively small (see Figs 5, 6, 8 and 11), the incorporation of the stiffness degradation on the structural response is less important, even that some increase in the peak displacement (on the order of 1-2\%) due to the degradation of horizontal stiffness has also been recordered (see Table 1). 




(a)

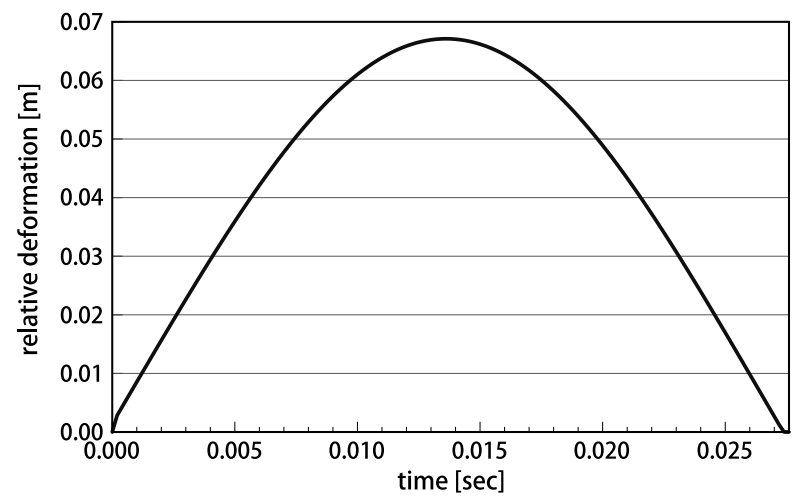

(b)

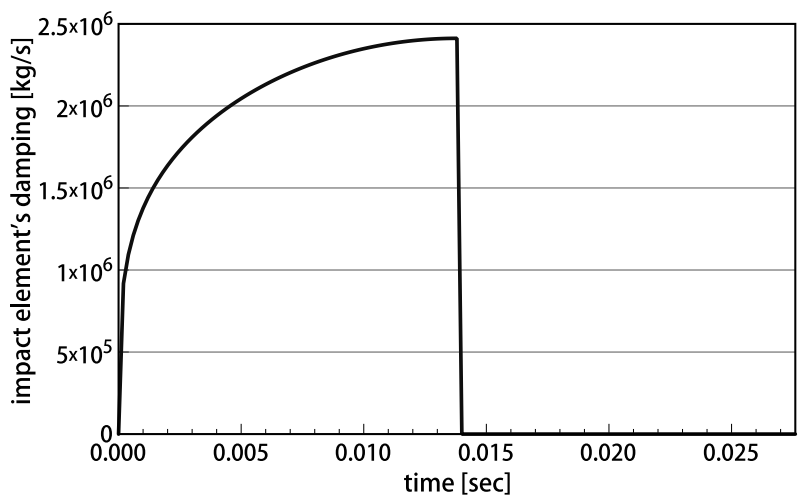

(c)

Fig. 14. Time histories during impact: (a) impact force; (b) relative vertical deformation of colliding structural members; (c) impact element's damping.

\section{Concluding remarks}

The behavior of the structural members of the building under earthquake excitation which are additionally subjected to vertical impact load after failure of the intermediate soft-story has been studied in this paper. Special attention has been paid to investigate the influence of the horizontal stiffness degradation of columns on the overall structural response during the ground motion. First, the theoretical approach to the problem of the column's deformation has been presented. Then, the numerical analysis concerning the behavior of a three-story building suffering from the earthquake-induced soft-story failure has been described.

The results of the study show that the degradation of horizontal stiffness of building columns, due to impact caused by the fall of the upper stories, may have a considerable influence on the structural response. Moreover, the results clearly indicate that the time of impact plays a substantial role in the overall behavior of a building under earthquake excitation. It has been shown that the structural response may be increased significantly if impact takes place when the structure is in the range of its peak deformations during the ground motion, especially when the structure is just approaching the extreme position. On the other hand, when impact takes place when the actual displacement of the building during earthquake is relatively small, the influence of the stiffness degradation on the structural response is less significant.

The study described in this paper has concerned the response of a three-story building modeled as a lumped mass system under unidirectional earthquake excitation. Moreover, only the degradation of horizontal stiffness of columns has been considered and the degradation of stiffness of joints (which might play an important role in the response of buildings under earthquake excitation) has not been considered in the numerical model. Further studies on more detailed structural models of different types of buildings under three-dimensional ground motion excitations are therefore required in order to extend our knowledge on behavior of buildings suffering from the soft-story failure during earthquakes. 


\section{References}

[1] B. Maison, D. Bonowitz, L. Kornfield and D. McCormick, Adjacency issues in soft-story wood-frame buildings, in: Report to Structural Engineers Association of Northern California, California, 2011.

[2] S. Elkholy and K. Meguro, Numerical simulation of high-rise steel buildings using improved applied element method, in: 13th World Conference on Earthquake Engineering, Vancouver, Canada, Paper No. 930, 2004.

[3] F. Watanabe, Behavior of reinforced concrete buildings during the Hyougoken-Nanbu earthquake, Cement Concrete Comp 19 (1997), $203-211$.

[4] A. Ghobarah, M. Saatcioglu and I. Nistor, The impact of the 26 December 2004 earthquake and tsunami on structures and infrastructure, Engineering Structures 28 (2006), 312-326.

[5] S.A. Anagnostopoulos, Pounding of buildings in series during earthquakes, Earthquake Engineering and Structural Dynamics 16 (1988), 443-456.

[6] R.O. Davis, Pounding of buildings modelled by an impact oscillator, Earthquake Engineering and Structural Dynamics 21 (1992), 253274.

[7] K.T. Chau and X.X. Wei, Pounding of structures modelled as non-linear impacts of two oscillators, Earthquake Engineering and Structural Dynamics 30 (2001), 633-651.

[8] A. Ruangrassamee and K. Kawashima, Relative displacement response spectra with pounding effect, Earthquake Engineering and Structural Dynamics 30 (2001), 1511-1538.

[9] S. Mahmoud, X. Chen and R. Jankowski, Structural pounding models with Hertz spring and nonlinear damper, Journal of Applied Sciences 8 (2008), 1850-1858.

[10] R. Jankowski, Experimental study on earthquake-induced pounding between structural elements made of different building materials, Earthquake Engineering and Structural Dynamics 39 (2010), 343-354.

[11] B.F. Maison and K. Kasai, Dynamics of pounding when two buildings collide, Earthquake Engineering and Structural Dynamics 21 (1992), 771-786

[12] S.A. Anagnostopoulos and K.V. Spiliopoulos, An investigation of earthquake induced pounding between adjacent buildings, Earthquake Engineering and Structural Dynamics 21 (1992), 289-302.

[13] C.G. Karayannis and M.J. Favvata, Earthquake-induced interaction between adjacent reinforced concrete structures with non-equal heights, Earthquake Engineering and Structural Dynamics 34 (2005), 1-20.

[14] S. Mahmoud and R. Jankowski, Pounding-involved response of isolated and non-isolated buildings under earthquake excitation, Earthquakes and Structures 1 (2010), 231-252.

[15] R. Jankowski, Nonlinear rate dependent model of high damping rubber bearing, Bulletin of Earthquake Engineering 1 (2003), $397-403$.

[16] M. Papadrakakis, C. Apostolopoulou, A. Zacharopoulos and S. Bitzarakis, Three-dimensional simulation of structural pounding during earthquakes, Journal of Engineering Mechanics 122 (1996), 423-431.

[17] R. Jankowski, Non-linear FEM analysis of earthquake-induced pounding between the main building and the stairway tower of the Olive View Hospital, Engineering Structures 31 (2009), 1851-1864.

[18] R. Jankowski, Non-linear FEM analysis of pounding-involved response of buildings under non-uniform earthquake excitation, Engineering Structures 37 (2012), 99-105.

[19] W. Migda and R. Jankowski, Behaviour of deformed steel columns exposed to impact load during earthquakes: Experimental study, Journal of Applied Sciences 12 (2012), 466-472

[20] E. Juhasova, Seismic effects on structures, Elsevier, International edition, 1991.

[21] S. Timoshenko and J. Gere, Theory of elastic stability, McGraw-Hill, New York, 1961

[22] C.G. Karayannis, M.J. Favvata and D.J. Kakaletsis, Seismic behaviour of infilled and pilotis RC frame structures with beam - column joint degradation effect, Engineering Structures 33 (2011), 2821-2831.

[23] R. Jankowski, Non-linear viscoelastic modelling of earthquake-induced structural pounding, Earthquake Engineering and Structural Dynamics 34 (2005), 595-611.

[24] N. Newmark, A method of computation for structural dynamics, Journal of Engineering Mechanics Division ASCE 85 (1959), $67-94$.

[25] A.K. Chopra, Dynamics of Structures: Theory and applications to earthquake engineering, Prentice-Hall, Englewood Cliffs, N.J., 1995. 

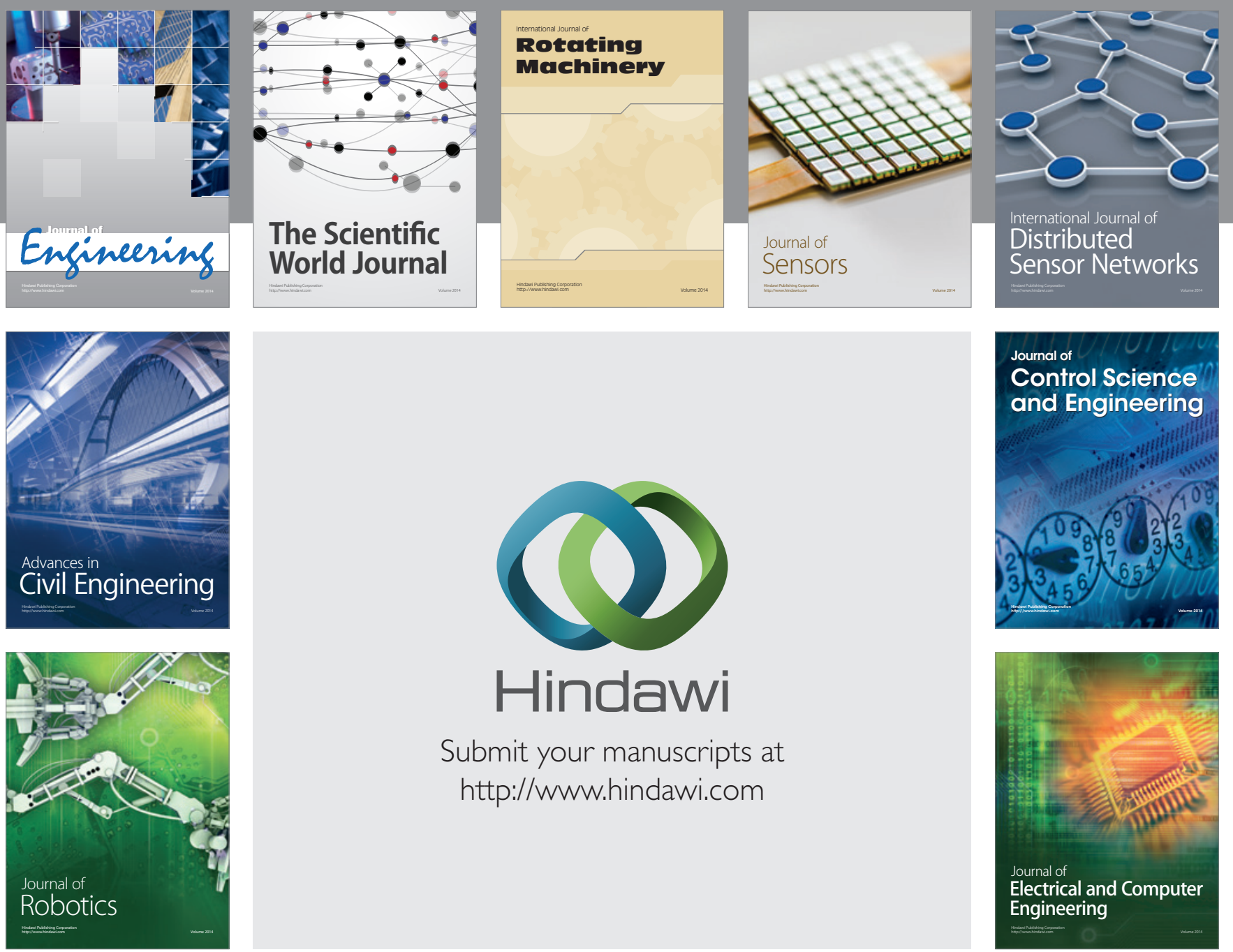

Submit your manuscripts at

http://www.hindawi.com
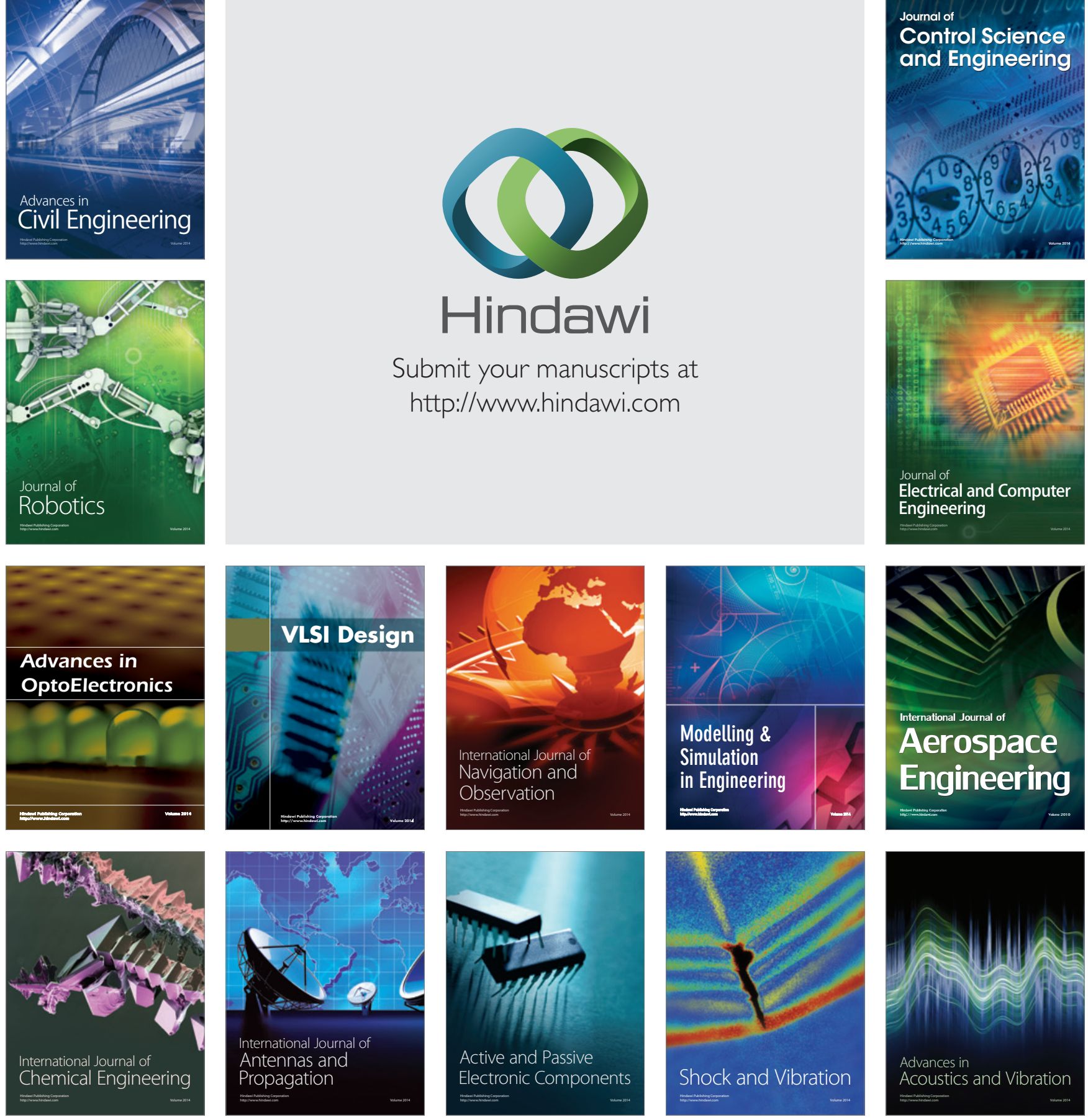